\title{
Economic and Environmental Evaluation of Nitrogen Fertilizer Taxation: A Review
}

\author{
Flavio Gazzani
}

\author{
Department of Economics and Law, University of Rome Sapienza, Italy
}

\begin{abstract}
Nitrogen fertilizers is an essential input into modern agriculture, however the use of large amounts of this mineral fertilizers caused in the last three decades enormous environmental impacts such as eutrophication of waters and soils, loss of biodiversity, drinking water pollution and human health risks. The agri-environmental policy plays a crucial role to internalize pollution externalities from agriculture production and ensuring food production and food price remain affordable even to those with lowest income.

To date, regulatory instruments, such as the Nitrate Directive in EU applied to reduce and manage nitrogen pollution run-off showed scarce results in terms of environmental protection and in many countries such as Ireland and Spain created evident loss of incomes and impose high costs on small to medium farmers to respect nitrogen fertilizers limits. Meanwhile in other countries economic instruments such as nitrogen taxation reach better results in terms of agriculture emissions reductions and environmental impacts due to their flexibility.

This review aims to document the current state of the knowledge of nitrogen taxation and gather experience from other countries for reducing nitrogen emissions assessing their effects on farmers' income productivity, food price stability and environmental outcomes.
\end{abstract}

Keywords-Nitrogen fertilizers, non-point source pollution, environmental regulation, nitrogen taxation.

\section{INTRODUCTION}

The agri-environmental policy instruments that aims to achieve sustainable environmental outcomes such as protecting drinking water from fertilizers pollution, reducing soil acidification and loss of soil's fertility and eutrophication of waters plays a crucial role in the agriculture sector to manage and reduce nitrogen pollution.Regulatory instrument, showed scarce environmental results to mitigate contamination of groundwater. Discharges from agriculture (fertilizers and animal wastes) are the largest source of nitrate contamination of groundwater, but there is no current or historic regulatory program that was able to reduce fertilizers runoff. Overall, nitrate concentrations in groundwater have not decreased in the last three decades. In fact, concentrations have even increased in some areas, such as in US, where the Clean Water Act failed to reduce nonpoint pollution for the agriculture sector after more than 30 years action and evidence is clearly showed in Mississippi River, Lake Erie, Chesapeake Bay and other several American rivers. This was due mainly for the fact that the Clean Water Act in US gives to the federal government little power to regulate agriculture pollution. Some regulatory programs have recently introduced mandatory monitoring programs, but monitoring alone will not improve water quality. Many years are needed for regulatory actions to reduce nitrate in groundwater and improve drinking water quality.

The physical properties of nitrate in groundwater mean that regulatory actions on nitrate leaching today will not bring drinking water sources into water quality compliance for years to decades. In Europe, the Nitrate Directive introduced in 1991 showed some improvement form the environmental point of view, but still very far to solve this problem, considering that in some area, such as the Baltic Sea, eutrophication increased consistently in the last twenty years. Evidence shows that benefits, in terms of nitrogen reduction are strongly affected by the environmental conditions and by the farming systems in Europe. Many European countries struggled to respects the standard and limit for nitrogen application, and state that comply within the limits presented high farmer income losses. In particular, dairy sector shows serious problems to implement Nitrate Directive, respect the limits and large negative distributional effects to farmer income.

Ireland represents afailure of this directive in terms of farmers income impact and nitrogen reduction, where farmers were reluctant to introduce this regulatory mechanism due to the high costs and the lack of government policy that really compensate farmers that respect this regulation that aims to increase the quality of water. Few States adopt the right-based approach that 
typically involve the imposition of a limit or 'cap' on pollution or polluting activities, either by specifying a total nitrogen and phosphorous pollution limit.

One of the most important tradable emission permits created to reduce and manage nitrogen pollution from agriculture activities is the Water Quality Trading (WQT) adopted in United States and Canada. Benefit from WQT was highlighted only in some regional areas such as in the Ontario South Nation River in Canada and Michigan and Colorado in US, and include not only improving water quality but also strengthening community relationships. Overall, the biggest impediment to WQT was the lack of public knowledge of benefits and in many cases around United States, the transaction costs were extremely high and was one of causes that limited this mechanism. Successful trading required the development of institutions for organizing trade that are trusted by and effective for intended program participants. Positive results seems arising from New Zealand innovation program in Lake Taupo, North Island, where the Water Trust provide farmers the option to change agriculture activities or pursue alternative land uses. Anyway, this mechanism need long period of activities before producing environmental benefits and the Phosphate Quota System in Germany and Nitrogen Quota System in Denmark failed to produce positive results due to the short period activities. It comes clear that there is no ideal solutions or best environmental policy instrument to reduce nitrate in groundwater. Environmental taxes, and in particular nitrogen taxation shows some positive and interesting results in terms of environmental outcomes, farm costs and income redistribution. The next following section presents some empirical studies of nitrogen taxation.

\section{EMPIRICAL ANALYSIS AND SIMULATIONS OF COMPARISON EFFECTS OF REGULATIONS AND HYPOTHETICAL INTRODUCTION OF NITROGEN TAXES}

The application of a tax on nitrogen fertilizers seems more effective in terms of fertilizers demand reduction and consequently environmental benefits, even if some economists disagree about the price elasticity of demand fertilizers and expected very low reduction in nitrogen volume. This section present international case studies that emphasize economics and environmental outcomes of nitrogen taxation using both bio-economic models and econometric analysis to estimate the impacts of fertilizers taxation on fertilizers demand, production, farm income and environmental aspects.

\section{Denmark}

The use of mineral fertilizers in Denmark has increased consistently until the 1980s due to the intensive crop production and caused extensive environmental impacts such as water pollution and euthrophication. Denmark introduced a tax on nitrogen in fertilizers in 1998 but due of its exemptions, in practice only household users pay tax and these users were generally unaware of the tax. Since the 1980s a sets of regulatory instruments and Government action plans were introduced to limit and ban nutrient losses in agriculture in Denmark. From 1990 to 2011 the use of imported nitrogen fertilizers dropped from 390,000 tons to 200,00 tons reaching a reduction of $42 \%$. The result of this environmental policy was considerably positive in terms of environmental benefits, but still very far from a sustainable solution.

In 2013,Skou Andersen et al. conducted an empirical analysis of extending nitrogen tax to farmers to reduce environmental impacts in Odense River Basin located in Denmark. The introduction of the nitrogen tax instead of the regulatory instrument would affect the price of imported mineral fertilizers, and therefore a reduction in their use (up to full elimination). This environmental tax would move farmers towards the use of organic fertilizers even if crop yields would decline relatively less however. So, nitrogen tax would not affect organic fertilizers such as waste product of animal husbandry, and their trade value could increase consistently. Skou Andersen et al. (2013) used an economic model to estimate the farmer income shock of introducing nitrogen taxation for the specific area and analyzed the impact on agriculture product prices. The results shown that the introduction of nitrogen taxation could increase the demand for organic fertilizers with a negative impact on imported mineral fertilizers and a significant environmental benefits in clean waters and drinking water.

Another important study conducted in Denmark on nitrogen taxation impact on crops and manure by Bernstenet al. in 2003. They used a whole farm model called FASSET (Farm Assessment Tool) developed by the Aarthus University in Denmark to evaluate consequence of changes in environmental regulations and the impacts on prices and subsides introducing nitrogen tax. In particular they analyzed the introduction of a tax on nitrogen in mineral fertilizer and a tax on the farm nitrogen surplus. In four different farm types such as arable on sandy soil, arable on loamy soil, pig production on sandy soil and pig 
production on loamy soil. From the empirical analysis none of the taxation measures was the most cost-effective for all farm types but they concluded that the environmental pollution reduction achieved with nitrogen taxation seems the best solution compared to other possible command and control mechanisms.

\section{Spain}

The Nitrate Directive and the more recent Water Framework Directive to limit nutrient losses to water bodies in agricultural land in Spain shown a very scarce results in terms of environmental benefits and imposed high costs on famers, especially those with small and medium size.

Martınez and Albiac (2006) developed and economic model to analyses the effects different environmental policy measures on agriculture production including the introduction of nitrogen tax. The economic model includes both corn production function and a nitrogen pollution function, in order to assess both the private benefits to farmers from corn production, and the damage cost to local communities from nitrogen pollution. Nitrogen taxation was considered the first best instrument of taxing $\mathrm{N}$ emissions, with a unit emission cost equal to $1.23 € / \mathrm{kg}$ (2005). The proposed nitrogen tax would strongly reduce nitrate losses, diminishing pollution levels by soil type between 10 and 60 percent. They also estimated that nitrogen tax could increase welfare in the district by 0.32 million euro. Their results indicated that a tax on mineral fertilizers and in particular the use of nitrogen results in more significant pollution reduction at much lower costs.

Gallego-Ayala and Gomez-Limon in 2009 compared the effects of the Common Agriculture Policy (CAP) in EU reform with alternative nitrogen taxation designed to mitigate nitrate pollution in agriculture sector in Spain. They estimated the economic, social and environmental impacts of the introduction of nitrogen fertilizers tax within the context of the new CAP. The first hypothetical scenario of an economic charge of $€ 0.20 \mathrm{~kg} \mathrm{~N}-1$ for nitrogen fertilizers would produce an irrelevant decrease in the use of mineral fertilizers and consequently irrelevant environmental benefits. However, an increasing value of taxation such as $€ 0.40 \mathrm{~kg} \mathrm{~N}-1$ would reach more than $50 \%$ reduction in the nitrate balance indicator, and reaching $64.4 \%$ for a charge of $€ 1.00 \mathrm{~kg} \mathrm{~N}-1$. The economic impact on farmer income seems consistent using nitrogen tax of $€ 0.40 \mathrm{~kg} \mathrm{~N}-1$ but could be compensated by the national Government incentives if the real aim is to reduce nitrate losses in to the waters.

\section{Switzerland}

Switzerland is another country that in the last two decades reported an increasing waters pollution caused by the losses of harmful nitrogen compounds from the agriculture. The agri-environmental policy in Switzerland to manage and reduce mineral fertilizers is based on regulation and restriction of nitrogen uses that vary on the type of farmer' activities and the regional areas. Due to the high farmers income compared to the other EU countries, the income variability is generally affected only by the extreme climatic events that rarely occurs. The idea of introducing nitrogen tax in Swiss agriculture is recently taken in consideration due to the scarce results from the currently regulations in terms of water quality improvement in rivers and lakes. Robert Finger (2012) in his study proposed the introduction of nitrogen tax in the Swiss Confederation, using a bio-economic model to investigate its economic and environmental impacts. The assumption was that if a nitrogen tax would be introduced, the nitrogen fertilizer demand decreases irrespectively of farmers' risk attitude. From his economic model simulation the three taxes option of $10 \%, 20 \%$ and $30 \%$ would reduce the nitrogen use respectively by about 5\%, 9,65\% and 13\%. From this economic analysis is evidenced that in this particular case, a small amount of nitrogen taxation is required to reach reduction of nitrogen use without presenting evident farmer' income losses.

\section{New Zealand}

According to the data provided by the Minister for the Environment of New Zealand the $39 \%$ of groundwater monitored in New Zealand (2015) have level of nitrate that are above natural background levels caused by leaching of mineral fertilizers and stock effluent causing aquatic pant growth such as in Lake Taupo (Ministry for the Environment NZ, 2015). Various regulatory instruments were introduced in New Zealand since the 1991 such as the Resource Management Act (1991), the Agricultural Compounds and Veterinary Medicines Act (1997) (ACVM), Agricultural Compounds and Veterinary Medicines Regulations (2001), the Hazardous Substances and New Organisms Act 1996 (HSNO), that aims to reduce nitrate leaching and guarantee good level of waters quality. These regulations and the nitrogen-trading program created several economic impacts on small and medium maori pastoral agriculture activities and in some region shown scarce results of emissions reduction.

Ramilanet al., 2007 conducted an empirical study on the nitrogen taxation impact in New Zealand, focus on a 
Waikato River Sub catchment using dairy farm as case study, considering that this agriculture activity is the predominant land use in this country. In fact, dairy farming in North Island is the predominant agricultural land use and occupy almost the $70 \%$. For the estimation of nitrogen taxation impact in dairy farming system, they used a whole farm model that takes into account agri-biological variable such as local climate, cow metabolism, pasture growth, paddock and economic variables. Nitrogen fertilizer application was limited at $200 \mathrm{~kg} / \mathrm{ha}$ in the optimization process except the intensive farming systems. Cameron $e t$ al (2003) suggested that nitrogen applications to pasture are most efficient when applied at rates of between 20 and 40 $\mathrm{kg} \mathrm{N}$ ha and should not exceed 150 to $200 \mathrm{~kg} \mathrm{~N} / \mathrm{ha}$. Even though the farming systems are not directly comparable due to the differences in soil and topographic characteristics, the results indicate differences among farms.

Ramilanet al. (2007) propose that the value of taxation should be differentiated by the different kind of farming systems and should be very high for extensive farms in New Zealand. An hypothetical tax of $\$ 5 \mathrm{~kg} \mathrm{~N}-1$ will cause a considerable reduction in mineral fertilizers demand and environmental benefits for low to moderate concentration farms, while for high intensive farm systems the tax value should be $\$ 15 \mathrm{~kg} \mathrm{~N}-1$ to reach the same results. They concluded that an efficient taxation scheme should be differentiated by farm types and level of nitrate emissions.

\section{South Korea}

South Korea agriculture sector is one of the most mineral fertilizers intensive users in the world. Water quality decreased consistently in the last three decades and agriculture emissions such as nitrogen and phosphorous are the principal pollutants causing eutrophication, losses of biodiversity in rivers and lakes and soil quality degradation. The use of phosphorous and nitrogen in the intensive agriculture excided the required for the optimal level and twice the amount used in EU countries.

To limit the environmental damages caused by the chemical fertilizers overuse, the Korean Government in 1993 introduced regulation and integrated nutrient management program to reduce the use of fertilizers. From 1995 to 2005 the average use of chemical fertilizers per hectare decreased from $424 \mathrm{~kg}$ to $376 \mathrm{~kg}$ (OECD, 2008). These regulation and eco-friendly management program show some interesting results in terms of chemical fertilizers demand reduction, but still very far from an efficient solution to protect the Korean waters from nitrate pollution.

Kim and Stoecker (2006) analyze the economic effect of the introduction of nitrogen tax on mineral fertilizers on rice production in South Korea, by using a partial equilibrium model. The model estimated the price elasticity of mineral fertilizers demand around 0.14 while the supply elasticity was 2.78. Introducing new nitrogen tax on mineral fertilizers farmers' welfare could decrease due to the increased fertilizers price and consequently the consumption should decrease.In relation to measuring the demand and supply elasticity for chemical fertilizers, they approached the demand side easily through survey data for the cost of rice production. The price elasticity of demand for chemical fertilizers was found to be 0.1456 and the supply elasticity was found to be 2.7875 . The study presented three different values taxation of imposing $10 \%$, $100 \%$ and $200 \%$ of tax increase and analyzed the impact on demand reduction and rice production.

The case of $10 \%$ tax increase, the fertilizers demand would decrease only by $1.5 \%$. In case of a $100 \%$ tax, demand would drop by $14.6 \%$ and this level of decrease in fertilization had almost no influence on the quantity of yield. A $200 \%$ tax would decrease the demand at $29.1 \%$ reducing the yield of $22 \%$.

They conclude that the case of $100 \%$ tax increase seems to be the more appropriate and efficient measure, because the decrease in farmer's income would be only $3 \%$ and the quantity of rice yield would be nearly unchanged.

\section{Nitrogen taxation welfare impacts}

Economic instruments such as nitrogen taxation to reduce and manage nutrient runoff from mineral fertilizer overuse have important advantages in environmental effectiveness and positive welfare effect to address water quality improvement, ability to raise public revenue and transparency. The aim of introducing nitrogen tax is to directly address the markets failure to take environmental impacts into account by incorporating these impacts into agriculture products prices. Considering that demand for mineral fertilizers and nitrogen in particular is very inelastic, to achieve reduction in application rate, high substantial taxation is required. Simulations and previous experience from countries that introduced nitrogen taxation, suggests that such tax should be applied at least at $100 \%$ rate. This taxation rate imposeslarge economic effects on farmers' income, especially farms with large livestock concentration. The most important aspect, before design and introduce nitrogen taxation, is to evaluate and differentiate the taxation rate related to the application rate 
and nutrient surplus per hectare. However, the negative effect of farmers' income loss caused by the tax since it increases their costs, could be compensated if government introduce a reimbursement to farmers. A large nitrogen taxation with reimbursement to farmers if well calibrated is a fair systems and able to strongly affect the demand of mineral fertilizers. En fact, fertilizers and feedstuff producers will be largely impacted, as farmers attitude will be to improve efficiency of nitrogen use to reduce their costs, and will substitute part of their fertilizers by manure and legumes and other organic feedstuff. This system will inevitably impact on mineral fertilizers sales and on mineral industry at large scale.

Increasing water quality and reducing the risks of chemical contaminations has a positive impact on society and in particular to rural residents. Estimating the monetary value of positive welfare effect, such as reducing algal blooms and eutrophication in a lake, can be estimated as the amount of society is willing to pay to gain water quality and save drinking water. In environmental economics, water quality improvement is defined as no-market value because there exist no markets and therefore no markets prices are available to estimate the economic value. The only way to assess the economic value of this environmental service is analyze the residents' willingness to pay to improve their environmental goods. Choice Modeling and Contingent Valuation represent the most important methodology approach to estimate in monetary value such environmental changes and nitrogen application reduction in agriculture areas. Poor et al. (2007) estimated the welfare benefit from increasing water quality of reducing nitrogen losses in Maryland waters in United States using hedonic price function where the price of residential property was regressed on the characteristics of environmental goods. This study show how water quality significantly influence residential property values and removing inorganic nitrogen from waters in Maryland increased the welfare household by $\$ 17,642$ USD in (2007).Ahlroth (2009) estimated the welfare benefits of increasing water quality in Baltic Sea waters in Sweden using contingent valuation methodology to assess the willingness to pay for reducing nitrogen and phosphorous agriculture emissions. The willingness to pay for improved water quality was estimated at $€ 270$ per person per year and this amount aggregated to national level reach $€ 1.8$ billion in 2009.Ik-Chang Choiet al. (2016) estimated the welfare benefits of improving water quality in tidal flat rural areas in South Korea using contingent valuation methodology, accounting $\$ 870$ million USD in welfare economic benefit per year (2012).

Increasing water quality and reducing mineral fertilizers losses affects many aspects of human well-being and costs and benefits impact on different groups of beneficiaries at different level. Water quality is highly valued by the public and welfare benefit is consequently very consistent in terms of economic value. Therefore, agri-environmental measure to reduce the application of mineral fertilizers and the water degradation play a crucial role to increase the welfare benefits.

\section{CONCLUSION AND POLICY RECOMMENDATIONS}

Mineral fertilizers emissions from agriculture increased strongly within the last three decade and will continue to grow in the near future as shown in US and many other Nordic countries in EU. Hence, the agricultural sector will continue to be one of the main drivers of water pollution across the globe. To date, current agri-environmental policy that introduced regulatory instruments and water quality trade systems failed in manage and control fertilizers runoff. However, there are economic instrumentsthat could help to reach a sustainable level of water pollution, such as the nitrogen taxation. By putting the price on mineral fertilizers, this instrument aims to shift nitrogen inputs from polluting chemical fertilizers to less polluting substitutes such as organic fertilizer and gives incentives to improve nitrogen efficiency. Environmental benefits and the degree of control of environmental pollution achieved with nitrogen taxation vary with the market price of the agriculture products and are affected by the fertilizers demand elasticity that is correlated to the farmers income.Due to the fact that demand for mineral fertilizer proved to be very inelastic, $-0,3-0,5$, therefore the tax rate needs to be high before the demand decreases. An appropriate level of charges is required to stimulate change in farmers' behaviour. This would make food more expensive because farmers would simply pass the increases cost of fertilizers onto the consumers and low income' people will be strongly affected. If we look for example the EU-28 economic situation in 2016, there are 122 million people at risk of poverty and increasing the food price to reduce fertilizers runoff seems completely inappropriate. So the crucial point is, considering that nitrogen taxation looks the more effective economic instrument to reduce mineral fertilizers demand, how we can compensate farmers losses and avoid that food price rise. Public financial support for eco-actions and trans-border cooperation programs are essential prerequisite to avoid 
impacts on farmer losses and food price. In fact nitrogen taxation can have adverse effects: unjustified income loss among certain groups of farmers, concentration of agricultural activity on a smaller area, and land abandonment in other regions, including regions where agriculture is vital for maintaining rural communities, cultural landscapes and biodiversity. Regressive impacts resulting from nitrogen pricing can be reduced through compensation, redistribute the revenues from the taxation to the farmers and by lowering taxes on employment and income. It comes clear, that the success and effectiveness of nitrogen taxation depends on how tax revenue will be distributed among the farmers (though tax rebate or incentives) who reduce mineral fertilizers demand and increase the demand of organic fertilizers. Same compensation mechanisms should be used among those farmers who invest in nitrogen recycle plants and removal technologies.

\section{REFERENCES}

[1] Ahlroth S(2009). Developing a weighting set based on monetary damage estimates. Method and case studies. ISSN: TRITA-INFRA-FMS 2009:1.

[2] Berntsen J, Petersen B., Jacobsen H, Olesen E, Hutchings $\mathrm{NJ}(2003)$. Evaluating nitrogen taxation scenarios using the dynamic whole farm simulation model FASSET. Agricultural Systems 76: 817-839.

[3] Cameron KC, Di HJ,Moir J(2003). Nitrogen: is it a SIDE issue? Paper presented at the South Island Dairy Event Conference 4.

http://researcharchive.lincoln.ac.nz/handle/10182/368 2.

[4] Finger R. (2012).Nitrogen use and the effects of nitrogen taxation under consideration of production and price risks.Agricultural Systems, 2012, 107: 1320.

[5] Gallego-Ayala J and Gómez-Limón A(2009). Analysis of policy instruments for control of nitrate pollution in irrigated agriculture in Castilla y León, Spain. Spanish Journal of Agricultural Research 2009 7(1): 24-40.

[6] Ik-Chang C, Hyun NK, Hio-Jung ., Tenhunen J.and Trung T. N. (2016). Willingness to Pay for a Highland Agricultural Restriction Policy to ImproveWater Quality in South Korea: Correcting Anomalous Preference in Contingent Valuation Method. Water 2016, 8, 547.

[7] Kim C.G. and Stoecker A. (2006).Economic Effects of Environmental Taxation on Chemical
Fertilizers.Journal of Rural Development 30(2): 1-18.

[8] Martinez Y., \&Albiac, J. (2006). Nitrate pollution control under soil heterogeneity. Land Use Policy, 23: 521-532.

[9] Ministry for the Environment New Zealand (2015). Environmental Indicators, a national environmental report published on 21 October 2015. Available on website: www.stats.govt.nz

[10] OECD (2008). Korea's Green Growth based on OECD Green Growth Indicators - Statistics Korea. Available on the website: www.oecd.org.

[11] Poor P.J, Pessagno K.L, and Paul R.V.,(2007). Exploring the hedonic value of ambient water quality: A local watershed-basedstudy. Ecological Economics 60: 797-806.

[12] Ramilan T, F. G. Scrimgeour, G. Levy and A. J. Romera(2007).Modelling Economic Impact of Agrienvironmental Policy on Dairy Farms. A Catchment Perspective.MODSIM 2007 International Congress on Modelling and Simulation.Modelling and Simulation Society of Australia and New Zealand, 1089-1095.

[13] Skou Andersen M., Ørsted Nielsen, H., Branth Pedersen A., Thodsen H., Pizzol M., FonnesbechWulff A., Block Hansen L., MolinasSenante M., (2013). Macroeconomic perspective on water quality and quantity issues of relevance to the System of Environmental-Economic Accounting for Water (SEEAW) Part A - Water Quality. 